\title{
Does pain necessarily have an affective component? Negative evidence from blink reflex experiments
}

\author{
Claudia Horn, Yvonne Blischke, Miriam Kunz PhD, Stefan Lautenbacher PhD
}

\author{
C Horn, Y Blischke, M Kunz, S Lautenbacher. Does pain necessarily \\ have an affective component? Negative evidence from blink reflex \\ experiments. Pain Res Manage 2012;17(1):15-24.
}

BACKGROUND: Experimental pain research has shown that the affective component of pain is influenced strongly by situational characteristics; affective pain processing appears to be particularly pronounced in situations that provoke a feeling of uncertainty and uncontrollability.

OBJECTIVES: To determine whether the affective component of pain can be completely abolished if a 'safe', particularly predictable stimulation paradigm is applied.

METHOD: Forty healthy volunteers recruited at the University of Bamberg (Bamberg, Germany) were assessed in two experiments. Tonic contact heat stimuli staged in three intensities (warmth, heat and pain) relative to the individual pain threshold was applied; these were predictable with regard to intensity and course, and the subjects had easy access to control. The startle reflex was assessed as an objective measure of affective response. In addition, the subjects provided unpleasantness ratings. To compare these results to a gold standard for affective response, affective pictures taken from the International Affective Picture System were presented during temperature stimulation in the second experiment.

RESULTS: Both experiments showed no potentiation of the startle reflex under painful heat stimulation compared with the two nonpainful stimulus intensities (heat and warmth), although the painful stimulation was clearly rated as more unpleasant.

CONCLUSIONS: Results suggest that it is possible to develop a 'safe' noxious stimulus, which is rated as clearly unpleasant, but lacks physiological indication of negative affect. This divergence might be explained by subjective ratings being influenced by the instructions. The possibility of reducing the pain affect by suggesting 'safety' may be of therapeutic interest.

Key Words: Affective pain processing; Affective pictures; Startle; Thermal pain

$\mathrm{t}$ is widely known that the experience of pain can be described using two separate dimensions: one relating mainly to sensory-discriminative aspects, and the other relating to the affective-motivational characteristics of pain perception. There is conclusive evidence that these two dimensions, sensory and affective-motivational, can dissociate, and that the affective-motivational component is strongly modulated by context and cognitive appraisal of pain.

This affective-motivational dimension can be determined at two stages of processing. The first stage comprises the immediate affective response to a noxious stimulus (commonly named 'pain unpleasantness'), while the second stage is reached when pain is of longer duration and associated with more complex emotional reactions such as frustration, depression and anger (1). Thus, the first stage of affective pain processing is believed to be passed while experiencing acute pain, whereas the second stage becomes only relevant in chronic pain. Accordingly, experimental noxious stimulation in healthy individuals - as used in the present study - allows only the study of first-stage responses.

In pain research, the sensory component is commonly represented by ratings of pain intensity, while the affective component is represented by ratings of pain unpleasantness. With regard to experimentally induced pain, individuals tend to give lower ratings for pain

\section{La douleur s'associe-t-elle nécessairement à un élément affectif ? Les preuves négatives tirées d'expériences sur le réflexe de clignement}

HISTORIQUE : Les recherches expérimentales sur la douleur révèlent que l'élément affectif de la douleur est fortement influencé par des caractéristiques situationnelles. Le traitement de la douleur affective semble être particulièrement prononcé dans les situations qui provoquent un sentiment d'incertitude et d'absence de contrôle.

OBJECTIFS : Déterminer si l'élément affectif de la douleur peut être aboli lorsqu'un paradigme de stimulation particulièrement prévisible et « sécuritaire " est mis en application.

MÉTHODOLOGIE : Quarante volontaires en santé recrutés à l'université de Bamberg (à Bamberg, en Allemagne) ont fait l'objet d'une évaluation dans le cadre de deux expériences. On leur a appliqué des stimuli de chaleur par contact tonique répartis en trois intensités (tiédeur, chaleur et douleur), selon leur seuil de douleur personnel. Ils étaient prévisibles sur le plan de l'intensité et de l'évolution, et les sujets avaient facilement accès aux réglages. Les chercheurs ont évalué le réflexe de sursaut comme mesure objective de la réponse affective. De plus, les sujets ont classé le caractère désagréable. Pour comparer ces résultats à une norme de réponse affective, on leur a présenté des images affectives tirées du système international d'images affectives pendant la stimulation par la douleur de la deuxième expérience.

RÉSULTATS : Les deux expériences n'ont révélé aucune potentialisation du réflexe de sursaut dans le cadre d'une stimulation de douleur par la chaleur par rapport aux deux intensités de stimulus non douloureux (chaleur et tiédeur), même si la stimulation de température était clairement classée comme plus désagréable.

CONCLUSIONS : D'après les résultats, il est possible de mettre au point un stimulus nuisible « sécuritaire », classé comme clairement déplaisant, mais il manque l'indication physiologique d'affect négatif. On peut expliquer cette divergence par des classements subjectifs influencés par les directives. La possibilité de réduire l'affect de douleur en suggérant la « sécurité » pourrait être intéressante sur le plan thérapeutique.

unpleasantness than for pain intensity, a phenomenon that is reversed in clinical pain settings $(2,3)$. This is probably because experimental pain is of known origin, and is much more predictable and controllable than clinical pain. However, even in response to experimental pain, subjects sometimes provide rather high unpleasantness ratings; in fact, there are several factors that are known to elicit higher degrees of unpleasantness in response to experimental pain. These variables apply to the physical characteristics of the stimulus itself as well as to the psychological manipulations of the experimental situation. Physical characteristics, which may be of relevance, are the intensity, localization and duration of stimuli. As one would expect, ratings of pain unpleasantness increase in parallel with stimulus intensity (4). However, localization and duration of noxious stimulation are also important: visceral pain is commonly experienced as more unpleasant than cutaneous pain $(5,6)$, and tonic noxious stimulation has been found to elicit higher degrees of pain unpleasantness than phasic stimulation (7-9). Psychological variables that affect the perceived unpleasantness of experimental pain are mood induction, predictability and the design of experimental instructions. It has been found that experimentally induced mood changes (using pleasant and unpleasant odours or pictorial scenes) preferentially modulate pain unpleasantness and not pain intensity $(10,11)$. Moreover, there is considerable 


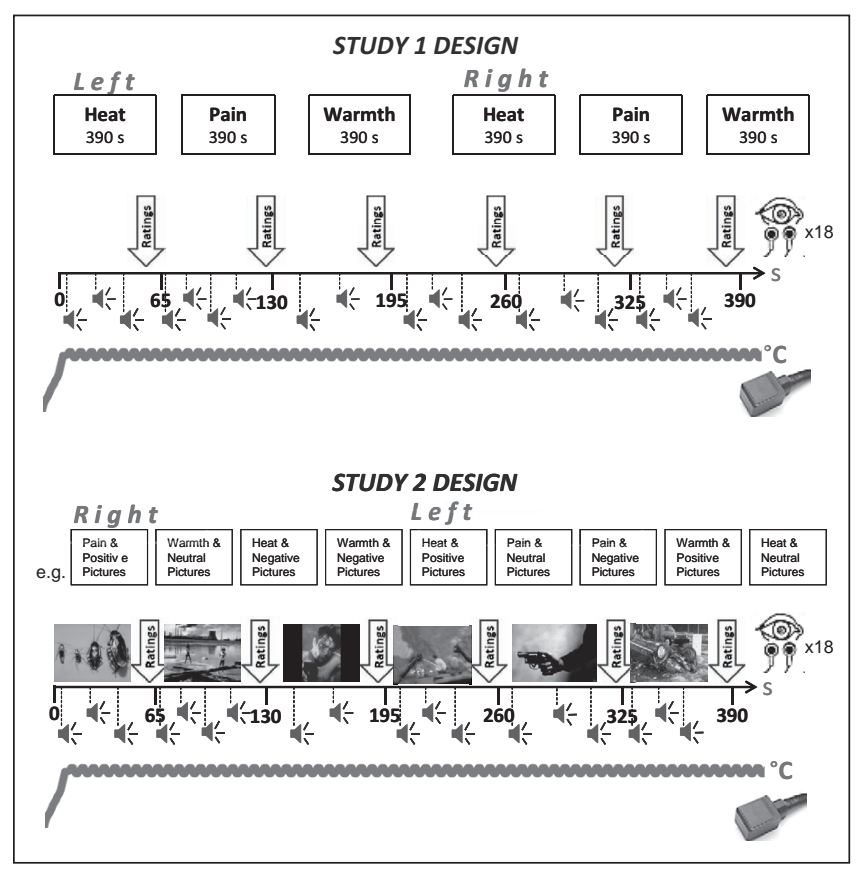

Figure 1) Experimental design of studies 1 and 2

evidence that the predictability of noxious stimuli plays a crucial role in determining the degree of elicited pain unpleasantness; stimuli that are preceded by a warning signal, and thus evoke less pain-related anxiety, are judged to be less unpleasant and evoke less activity in brain areas associated with affective pain processing than stimuli that are unpredictable to the subject $(12-14)$. Unpleasantness can also be enhanced via the content of experimental instructions. Participants who received threatening instructions before being administered a cold pressor task, thus evoking higher levels of anxiety, showed lower pain tolerance and a bias to affective pain words in the dot-probe task $(15,16)$.

All of these findings suggest that designing a 'safe' experimental situation in which the noxious stimuli are predictable with regard to intensity and course, and where the participants have easy access to control, should elicit very low degrees of pain unpleasantness. It may even be possible that in such a 'safe' situation, the affective component of pain processing can be reduced to a degree whereby an affective reaction to noxious stimulation is no longer measurable. However, this hypothesis cannot be tested when solely relying on self-report measures, because these are strongly influenced by task demands. More precisely, there is evidence that subjects have a tendency to judge pain intensity differently from unpleasantness whenever separate rating scales for both dimensions are presented concurrently. In contrast, if subjects rate either unpleasantness or intensity in different trials or if ratings of intensity and unpleasantness are obtained separately in two sessions one week apart, both dimensions are rated quite similarly $(17,18)$. These results might suggest that subjects artificially differentiate between unpleasantness and intensity - even if both dimensions are very similar - as soon as they are asked to rate two separate dimensions. To avoid such biases, it seems logical to use assessment methods that are less suggestive. Therefore, we decided to assess affective pain processing using an objective psychophysiological measure in addition to subjective ratings, namely, the eye-blink component of the startle reflex.

There is considerable evidence that the eye blink reflex can be modulated by the affective state of the subject. It is widely known that the startle reaction is intensified by fear (fear-potentiated startle [19]); however, startle potentiation is not specific to fear, but also applies to other negative emotions such as anger or disgust (20). Conversely, positive affect leads to startle inhibition compared with a neutral state. Thus, if pain per se is able to trigger negative affective responding, the startle reflex should be potentiated by noxious stimulation as well.
Crombez et al (21) already succeeded in modulating the startle reflex by applying painful heat. In their study, subjects were exposed to short bursts of radiant heat stimuli that were either painful or not. The authors found a potentiation of the startle reflex for painful compared with nonpainful stimuli. However, in their experimental paradigm, stimuli of different intensities were presented in random order, so that subjects were not able to predict whether the upcoming stimulus would be painful. Thus, we assume that the threat value was relatively high in this experiment, so that affective responding might have been triggered by situational characteristics rather than by the noxious stimuli themselves.

Our aim was to establish a 'safe' pain setting and to test whether this rather 'safe' noxious stimulation would elicit high unpleasantness ratings and, concurrently, potentiate the startle reflex (as an objective measure of affective responding).

In experiment 1, we aimed to develop such a 'safe' pain induction paradigm by applying tonic heat pain stimuli of known intensity and course with easy access to control. We did this by familiarizing subjects to this procedure in a practice trial and by emphasizing that stimulation intensity could be decreased if tolerance was reached. In experiment 2, affective pictures were added and compared as a further independent influence on affective responding. These pictures have become a gold standard for affective responding. If we are able to show that our 'safe' noxious stimulation does not elicit an affective component of pain, the hypothesis of the omnipresence of an affective pain component will be challenged.

\section{EXPERIMENT 1: METHODS}

\section{Subjects}

Forty subjects (20 female, 20 male, mean [ \pm SD] age $24.6 \pm 6.1$ years), mostly psychology students, were recruited via advertisements posted in the University of Bamburg (Bamberg, Germany) buildings. None suffered from severe acute or chronic illness, mental disorders or facial paralysis, and none had taken any drugs or consumed alcoholic beverages at least $12 \mathrm{~h}$ before testing. Because contact lenses are known to enhance blink frequency, persons wearing contact lenses were asked to instead wear their eye glasses during the experimental session. Fourteen women took oral contraceptives. For those who did not, the test sessions were equally distributed across the three different phases (menstrual, ovulatory and luteal phase) of the menstrual cycle. Before the test session, participants provided written informed consent. Some subjects were reimbursed for participation $(n=11)$; the others received course credits $(n=29)$. The experimental procedure was approved by the local ethics committee.

\section{Procedure}

Experimental sessions were conducted either in the morning or in the afternoon. Because the hour of testing can affect pain processing, an equal number of subjects were scheduled for investigations in the morning and in the afternoon.

Startle blink amplitude was measured during tonic temperature stimulation using three different temperature intensities ('warmth', 'heat' and 'pain'). Each of these temperature conditions was conducted twice, once on the left thigh (initial three trials = first block) and once on the right thigh (final three trials = second block) (Figure 1). Subjects were seated upright in a comfortable chair and were not able to see the temperature readout displayed on a PC monitor. After a practice trial that was designed to familiarize the participant with temperature stimulation and rating procedure, the experimental trials were started.

Thermal stimulation: Thermal stimulation was conducted on the subject's thigh using a Peltier-based contact stimulation device (TSA2001, Medoc, Israel) with a $30 \mathrm{~mm} \times 30 \mathrm{~mm}$ contact thermode. The thigh was used for thermal stimulation because this area provides enough space to be divided in three subsections (distal, central and proximal) so that thermode position could be changed after completion of each trial. This procedure is important to avoid local 
sensitization. Because stimulus intensities were tailored to the pain threshold, threshold estimation always preceded tonic stimulation. Heat pain threshold was assessed using the method of adjustment. Subjects were asked to adjust the temperature starting from $35^{\circ} \mathrm{C}$, using heating and cooling buttons, until they obtained a level that was barely painful. A constant press of the buttons resulted in the heating or cooling of the probe at a rate of $0.5^{\circ} \mathrm{C} / \mathrm{s}$. Following a familiarization trial, there were six trials and the average of the last five trials was used to constitute the threshold estimate. Pain threshold was measured first on the left thigh.

Tonic heat stimuli were administered according to the protocol of the Tonic Heat Pain Model (9). Small heat pulses with an amplitude of $1.3^{\circ} \mathrm{C}$ were administered at a constant frequency of 30 pulses $/ \mathrm{min}$. Pulsating heat has the advantage of maximizing painfulness at lower levels of thermal stimulation. The perceptual correlate changes, however, very slowly and smoothly over minutes, if it changes at all, and is best described as constant thermal sensation, far from any rapid and surprising changes. For 'pain', the pulses (saw-tooth shape) were tailored to peak $1^{\circ} \mathrm{C}$ above the individual's pain threshold and for 'heat' and 'warmth', the procedure was the same with the exception that the temperatures peaked $1^{\circ} \mathrm{C}$ and $3^{\circ} \mathrm{C}$ below the individual's pain threshold. Thermal stimulation lasted $6.5 \mathrm{~min}$ in all three temperature conditions. The temperature increased from baseline with a rate of rise of $0.5^{\circ} \mathrm{C} / \mathrm{s}$ to the preset temperatures and returned with the same rate.

To boost the impression of safety, subjects underwent a complete practice trial with a stimulation temperature set at a pain threshold level (so they knew the intensity and course of the painful stimulation beforehand) and were informed that they could ask for a reduction in stimulus intensity if it became unbearable at any time during the stimulation trials (easy access to control).

Presentation of startle probes: To elicit the blink reflex, brief acoustic stimuli (white noise) were applied, $50 \mathrm{~ms}$ in duration, with an intensity of $105 \mathrm{db}$ binaurally over headphones. Subjects wore headphones during the entire experimental session, over which they heard constant white noise of $68 \mathrm{db}$ as masking background noise. During each trial of tonic thermal stimulation, 18 startle tones were delivered (Figure 1). Because every temperature condition was conducted twice, there were $2 \times 18$ probes per condition. They were timed in random intervals to be unpredictable. It was determined that there should be two to four tones per minute (Figure 1), the first tone of each minute should be presented after $3 \mathrm{~s}$ at the earliest and after $15 \mathrm{~s}$ at the latest, and the interstimulus interval should be at least $12 \mathrm{~s}$ to avoid habituation. Furthermore, there should be no tone presentation during the rating period. For each trial, the presentation time of startle probes was identical.

Rating procedure: At intervals of $55 \mathrm{~s}$ (six times collectively in each trial), participants rated the average unpleasantness of the temperature and startle tones of this interval on computerized numerical rating scales ranging from 0 (not unpleasant at all) to 10 (extremely unpleasant). Rating periods lasted for $10 \mathrm{~s}$. Therefore, the complete cycle of assessing startling $(55 \mathrm{~s})$ and rating $(10 \mathrm{~s})$ took up to $65 \mathrm{~s}$ and was repeated six times.

Electromyographic recording and analysis: Startle blinks were measured by recording surface electromyography (EMG) activity on the orbicularis oculi muscle beneath the right eye. For that purpose, $\mathrm{Ag} / \mathrm{AgCl}$ electrodes filled with electrode paste were used. Before application of the electrodes, the skin was cleaned with an alcoholic skin detergent to reduce electrode resistance. EMG raw signals were recorded using the SIGMA Plpro/Type Databox DB 36 including a 16 bit analogueto-digital converter with a dynamic range from $0.5 \mu \mathrm{V}$ to $2 \mathrm{mV}$. The recording bandwidth of the EMG signal was between $0.2 \mathrm{~Hz}$ and $300 \mathrm{~Hz}$; input resistance was greater than $20 \mathrm{mOhm}$. The signal was sampled at $512 \mathrm{~Hz}$. To enable event-related signal analysis, trigger signals were set to mark the onset of the startle tone.

After recording, the raw signal was analyzed offline using the Vision Analyzer program (Brain Products, Germany). First, the signal was divided into segments, each containing the EMG response to one startle probe. In each segment the raw signal was filtered using a $50 \mathrm{~Hz}$ notch filter, a $20 \mathrm{~Hz}$ high-pass filter and a $256 \mathrm{~Hz}$ low-pass filter, rectified and integrated. The signal was integrated over a time interval of $0 \mathrm{~ms}$ to $250 \mathrm{~ms}$. Responses were labelled as invalid and discarded from further analyses if considerable fluctuations in the baseline EMG activity were detected, if the peak of activity did not occur in the predefined time window of $30 \mathrm{~ms}$ to $100 \mathrm{~ms}$ after stimulus onset, or if they did not match the typical shape of a startle response.

The critical variables were latency and amplitude of blink responses. Latency was defined as the time from startle tone onset to the maximum value of voltage. Amplitude was defined as the voltage difference between the averaged baseline and the voltage peak within a time frame of $30 \mathrm{~ms}$ to $100 \mathrm{~ms}$ after startle tone onset. The mean values of latency and amplitude were calculated for each of the six trials and then entered into statistical analysis.

Because conditions were not scheduled in a balanced order and psychophysiological measures such as the blink reflex are known to habituate over time, the data were verified for time-related trends over each session. Small but significant correlations between the number of trials and startle blink amplitude were observed. Detrending of EMG data was performed using linear regression analyses, and nonstandardized residuals were used for further analyses.

\section{Statistics:}

Subjective unpleasantness ratings: To evaluate the effects of temperature conditions and of the tones on subjective unpleasantness ratings, ANOVAs with repeated measurements 3 ('temperature condition': 'pain', 'heat', 'warmth') $\times 2$ ('body side': 'right leg', 'left leg') were conducted.

Startle response: To evaluate the effects on startle latency and amplitude, 3 ('temperature condition': 'pain', 'heat', 'warmth') $\times 2$ ('body side': 'right leg', 'left leg') repeated measurement ANOVAs were conducted.

Adjusting degrees of freedom with Greenhouse-Geisser correction was necessary when sphericity could not be observed. In case of significant results, post hoc tests (paired samples $t$ tests) were computed. For F-tests, partial eta squared $\left(\eta^{2}\right)$ is reported as an estimate of effect size. In the case of $t$ tests, Cohen's $\mathrm{d}$ is reported. SPSS version 11.5 (IBM Corporation, USA) was used for all calculations; significant effects were assumed at $\alpha=0.05$.

\section{Subjective unpleasantness ratings}

Temperature ratings: With regard to temperature ratings, the ANOVA yielded a highly significant main effect of temperature condition (Table 1). In agreement with previous findings, subjects rated the 'pain' condition as quite unpleasant (mean \pm SD 5.54 \pm 2.22 ), with lower ratings for 'heat' $(3.59 \pm 1.98)$ followed by 'warmth' $(2.74 \pm 1.69)$. Post hoc tests showed that temperature ratings for the 'pain' condition were significantly higher than those for the 'heat' $(t[39]=7.28$, $\mathrm{P}<0.001, \mathrm{~d}=1.03)$ and 'warmth' $(t[39]=9.78, \mathrm{P}<0.001, \mathrm{~d}=1.55)$ conditions as well as ratings for the 'heat' condition were significantly higher than those for the 'warmth' condition $(t[39]=3.20, \mathrm{P}=0.003$, $\mathrm{d}=0.48$ ).

A significant main effect of body side and a significant interaction between both variables were also found (Table 1). However, because these were of no interest for the present study, there will be no further comment on these findings.

Tone unpleasantness ratings: The ANOVA yielded a significant main effect of temperature condition on tone ratings (Table 1). Startle tones were rated as significantly more unpleasant during the 'heat' $(6.68 \pm 2.01)$ condition than during the 'warmth' $(6.26 \pm 2.39)$ condition $(t[39]=2.14, \mathrm{P}=0.038, \mathrm{~d}=0.18)$. There were, however, no significant differences between 'pain' $(6.52 \pm 2.26)$ and 'heat' or 'pain' and 'warmth'. None of the other effects reached significance $(\mathrm{P}>0.05)$.

\section{Startle reflex}

Startle reflex latency: The ANOVA yielded no significant effects 
TABLE 1

Results of repeated measurement ANOVAs for the effects of temperature and body side on subjective ratings and startle reflex measures in experiment 1

Effects of independent variables on temperature ratings

\begin{tabular}{lcccr}
\hline & $\mathbf{d f}$ & $\mathbf{F}$ & $\mathbf{n}^{\mathbf{2}}$ & $\mathbf{P}$ \\
\hline Temperature & 2,74 & 54.45 & 0.10 & $<0.001$ \\
Body side & 1,37 & 4.67 & 0.11 & 0.037 \\
Temperature*body side & 2,74 & 12.75 & 0.26 & $<0.001$ \\
Effects of independent variables on tone ratings & &
\end{tabular}

Effects of independent variables on tone ratings

\begin{tabular}{lcccc}
\hline & $\mathbf{d f}$ & $\mathbf{F}$ & $\mathbf{\eta}^{2}$ & $\mathbf{P}$ \\
\hline Temperature & 2,66 & 3.66 & 0.10 & 0.031 \\
Body side & 1,33 & 0.94 & 0.03 & 0.340 \\
Temperature*body side & 2,66 & 1.37 & 0.04 & 0.261
\end{tabular}

Effects of independent variables on startle reflex latency

\begin{tabular}{lcccc}
\hline & $\mathbf{d f}$ & $\mathbf{F}$ & $\boldsymbol{\eta}^{2}$ & $\mathbf{P}$ \\
\hline Temperature & 2,58 & 0.36 & 0.01 & 0.701 \\
Body side & 1,29 & 0.75 & 0.03 & 0.392 \\
Temperature*body side & $1.46,42.29$ & 0.79 & 0.03 & 0.425
\end{tabular}

Effects of independent variables on startle reflex amplitude

\begin{tabular}{lcccc}
\hline & $\mathbf{d f}$ & $\mathbf{F}$ & $\mathbf{\eta}^{2}$ & $\mathbf{P}$ \\
\hline Temperature & $1.58,45.84$ & 8.80 & 0.23 & 0.001 \\
Body side & 1,29 & 0.56 & 0.02 & 0.460 \\
Temperature*body side & 2,58 & 2.84 & 0.09 & 0.067 \\
\hline
\end{tabular}

Significance set at $P<0.05$

when startle reflex latency was used as dependent variable (all $P>0.05$ ). Thus, there were no significant main and interaction effects of 'temperature' or 'body side'. Descriptive statistics of eye blink latency are shown in Table 2.

Startle reflex amplitude: For startle reflex amplitude, the ANOVA yielded a highly significant main effect for 'temperature condition' (Table 1). Descriptive data (Table 2 and Figure 2) and post hoc comparisons using paired sample $t$ tests showed that startle reflex amplitude was significantly higher for 'heat' than 'pain' $(t[37]=3.03$; $\mathrm{P}=0.004, \mathrm{~d}=0.21$ ) and significantly higher for 'heat' compared to 'warmth' $(t[38]=3.55 ; \mathrm{P}=0.001, \mathrm{~d}=0.25)$. The comparison between 'pain' and 'warmth', as well as other subtests of ANOVA failed to reach the level of significance. Thus, a modulating effect of temperature stimulation on startle reflex amplitude was found. However, in contrast to expectation and in contrast to the subjective unpleasantness ratings, blink reflex amplitude was higher in the 'heat' than in the 'pain' condition (see "Subjective unpleasantness ratings" above).

Summary of important findings in experiment 1 and rationale for experiment 2

Experiment 1 investigated whether tonic heat pain is able to potentiate the startle reflex. Surprisingly, a potentiation of the startle reflex under nonpainful heat compared with painful heat was observed, which is not consistent with the assumption that only pain contains an affective component with negative valence and not sensations induced by lower stimulation intensities.

Because this pattern of results was unexpected and almost paradoxical, we thought it urgently necessary to replicate this result in an

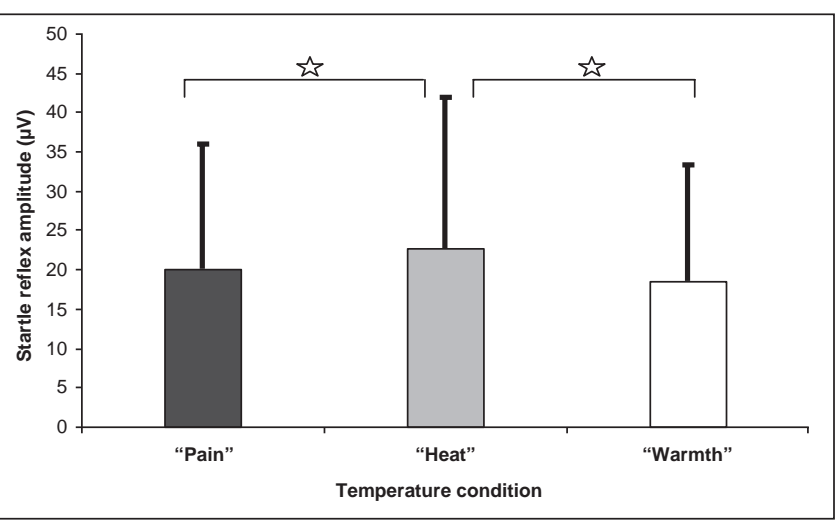

Figure 2) Mean \pm SD of startle reflex amplitudes for each temperature condition of experiment 1

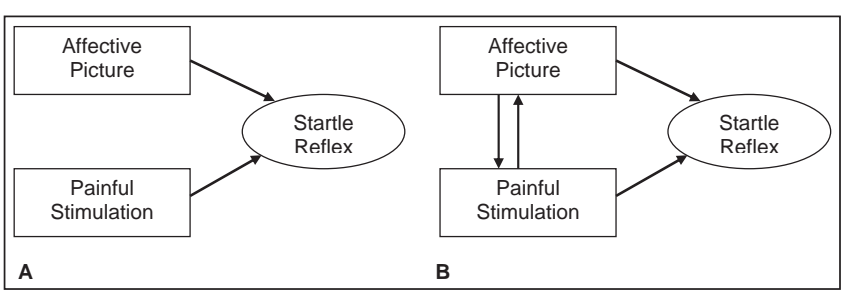

Figure 3) Effects of affective pictures and thermal stimulation on the amplitude of the startle reflex. Two possible effects can be expected: A Independent effects, B Interactive effects

independent sample of individuals before far-reaching interpretations were entertained. For a solid base of interpretations, we also planned to compare the startle responses to our tonic thermal pain with a gold standard of affective responding, namely, with the startle responses to affective pictures. In addition, we were interested in potential interaction effects between pain and pictures. For these reasons, it was decided to conduct the second experiment, which is described in detail below.

\section{EXPERIMENT 2: INTRODUCTION}

Affective pictures are known as the classical modulator of the startle reflex; the modulatory effect of picture valence on startle blink amplitude (motivational priming effect) has been replicated in many laboratories (22-25). Because experiment 1 indicated that the startle reflex can also be modulated by thermal stimulation, we were interested in the effects of presenting affective pictures and thermal stimuli concurrently. This concurrent presentation might result in independent effects (indicated by two significant main effects without a significant interaction), or unique and interactive effects of thermal stimulation and affective pictures on the startle reflex (indicated by two significant main effects and a significant interaction) (Figure 3). Because several researchers found a modulation of pain perception by emotion (26-30) and there is also some evidence suggesting that pain can modulate affective processing as well (31), we hypothesized that we would detect interactive effects of thermal stimulation and affective pictures on the startle reflex.

\section{TABLE 2}

Descriptive statistics of startle reflex latency and amplitude for each side of thermal stimulation and temperature condition in experiment 1

\begin{tabular}{|c|c|c|c|c|c|c|c|}
\hline & & \multicolumn{3}{|c|}{ Left leg stimulation } & \multicolumn{3}{|c|}{ Right leg stimulation } \\
\hline & & Warmth & Heat & Pain & Warmth & Heat & Pain \\
\hline \multirow[t]{2}{*}{ Latency, ms } & Mean & 57.77 & 55.10 & 57.08 & 57.85 & 58.03 & 57.05 \\
\hline & SD & 8.45 & 11.43 & 8.23 & 10.72 & 12.13 & 7.47 \\
\hline \multirow[t]{2}{*}{ Amplitude, $\mu \mathrm{V}$} & Mean & 17.54 & 23.30 & 20.27 & 21.48 & 24.00 & 21.28 \\
\hline & $\mathrm{SD}$ & 16.56 & 20.94 & 17.40 & 13.71 & 18.75 & 15.05 \\
\hline
\end{tabular}


To investigate the hypothesized interaction effects, we presented affective pictures taken from the International Affective Picture System (IAPS) (32) during temperature stimulation (Figure 1). We combined the three categories of affective pictures (negative, neutral and positive) with the three temperature conditions (warmth, heat and pain) established in experiment 1 in a factorial design. The 'warmth' condition with low levels of emotional valence served as a kind of neutral control condition to assess more selectively the emotional impact elicited by the affective pictures. Similarly, neutral pictures provided a neutral control condition to assess more selectively the emotional impact of thermal stimulation.

\section{EXPERIMENT 2: METHODS}

\section{Subjects}

Forty participants (20 male, 20 female; mean $[ \pm$ SD] age $23.7 \pm 4.44$ years), recruited at the University of Bamberg, participated in the study. Exclusion and inclusion criteria, and procedures before the test session (eg, written informed consent) as well as reimbursement were equivalent to those in experiment 1.

\section{Procedure}

In experiment 2 , all testing was conducted in the morning (08:00 to 12:00) and lasted for approximately $2.5 \mathrm{~h}$. The testing procedure was similar to that in experiment 1 . In addition, affective pictures were shown on a computer screen positioned in front of the participant (Figure 1).

To assess potentially additive effects of painful thermal stimulation and affective pictures, three picture valences (positive, negative and neutral) were combined with three levels of temperature intensity (warmth, heat and pain), resulting in nine experimental trials, each lasting $6.5 \mathrm{~min}$. These nine experimental trials were: warmth/neutral pictures, warmth/positive pictures, warmth/negative pictures, heat/ neutral pictures, heat/positive pictures, heat/negative pictures, pain/ neutral pictures, pain/positive pictures and pain/negative pictures. Because the condition 'warmth' was associated with very low unpleasantness ratings in experiment 1 , this condition was considered to be suitable to serve as a neutral control condition for the pure picture effects. The same was true for the trials in which neutral pictures were shown; they served as a control for the pure thermal effects.

During each trial, six pictures belonging to the same affective category were shown (Figure 1). Each picture was presented for $55 \mathrm{~s}$, followed by a $10 \mathrm{~s}$ rating period. The full cycle lasted $65 \mathrm{~s}$ and was repeated six times. The sequence of experimental trials was randomized across subjects.

Thermal stimulation: For thermal stimulation, the same device and stimulation protocol as in experiment 1 was used. The only difference was that the sequence of stimulated body sites was reversed; the experiments were first conducted on the right thigh and then changed to the left thigh (Figure 1). Thermode position was changed after each experimental trial to avoid sensitization.

Picture presentation: Affective pictures were preselected from the IAPS (32) on the basis of average valence and arousal ratings displayed in the manual. Pictures with moderate affective intensity were chosen to match the likewise moderate unpleasantness of the applied painful stimuli. Accordingly, the range of valence ratings for the affective categories were defined as follows: negative pictures ranging from 2.3 to 3.3 , neutral pictures ranging from 4.3 to 5.0 and positive pictures ranging from 6.0 to 7.0. Arousal ratings for positive and negative pictures were required to be approximately equal and ranged from 4.6 to 6.0 to exclude possible confounding effects by picture-induced arousal. This selection procedure resulted in 75 pictures ( 25 for each valence category), which were rated in a pretest by 10 student participants using a computerized version of the Self-Assessment Manikin (33). Because all average ratings reported in the IAPS manual were obtained in the United States, it was decided to run this pretest to make sure that the picture selection was suitable for use in German undergraduates.

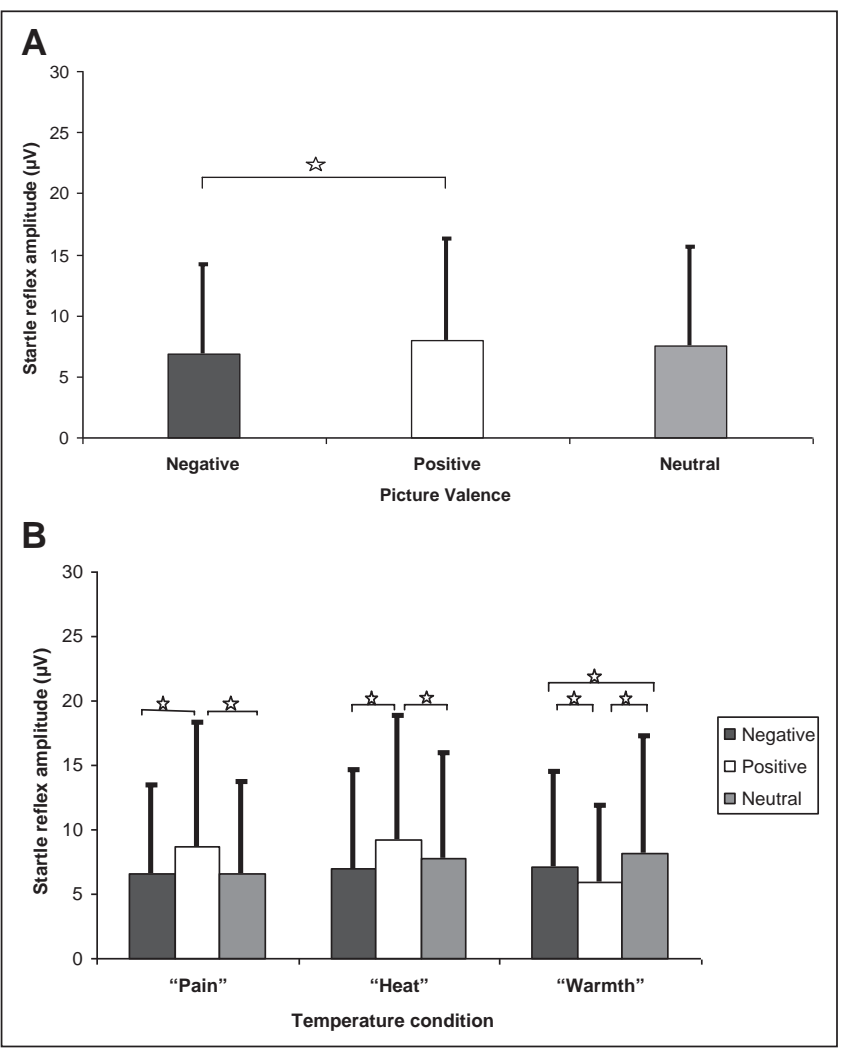

Figure 4) Modulation of the amplitude of the startle reflex in experiment 2. A Mean \pm SD of startle reflex amplitudes given for each picture valence condition (main effect of picture valence). B Mean \pm SD of startle reflex amplitudes given for each temperature and each picture valence condition (interaction effects)

Guided by the results of the pretest, 54 pictures ( 18 for each category) (Appendix 1) with average ratings closest to the predefined ranges were selected for the main experiment and were randomized in sequence within the three affective categories.

Startle probes: Startle probes (50 ms bursts of white noise, $105 \mathrm{db}$ ) were applied in exactly the same way as in experiment 1 (Figure 1).

Subjective ratings: As in experiment 1 , there were rating periods of $10 \mathrm{~s}$ following the $55 \mathrm{~s}$ of assessing startle responses. These cycles of $65 \mathrm{~s}$ were repeated six times. In addition to rating the unpleasantness of temperature and startle tones, participants now also had to rate the unpleasantness of the pictures, thus resulting in three 11-point computerized numerical rating scales $(0=$ not unpleasant at all; $10=$ extremely unpleasant).

EMG recording and analysis: EMG recording and analysis was conducted identically to the procedure in experiment 1 except for the detrending procedure, which was not necessary because the order of conditions was now randomized across subjects and thus potential order effects could be excluded.

\section{Statistics:}

Subjective unpleasantness ratings: To evaluate effects of 'temperature condition' and 'picture valence' on subjective unpleasantness ratings (temperature, tones and pictures), 3 ('temperature condition': 'pain', 'heat', 'warmth') $\times 3$ ('picture valence': 'negative', 'positive', 'neutral') repeated measurement ANOVAs were conducted.

Startle reflex: To test whether independent or interactive effects of 'temperature condition' and 'picture valence' on startle reflex latency and amplitude would occur (see "Experiment 2: Introduction" above, and Figure 3), 3 ('temperature condition': 'pain', 'heat', 'warmth') $\times 3$ ('picture valence': 'negative', 'positive', 'neutral') repeated measurement ANOVAs were conducted. Because 'body side' did not yield a significant main effect on startle in experiment 1 , this within-subject factor was eliminated in the present analysis to maximize statistical power. 


\section{TABLE 3}

Results of repeated measurement ANOVAs for the effects of temperature and picture valence on subjective ratings and startle reflex measures in experiment 2

Effects of independent variables on temperature ratings

\begin{tabular}{lcccc}
\hline & $\mathbf{d f}$ & $\mathbf{F}$ & $\mathbf{\eta}^{\mathbf{2}}$ & $\mathbf{P}$ \\
\hline Temperature & $1.34,52.40$ & 77.89 & 0.67 & $<0.001$ \\
Picture valence & 2,78 & 0.09 & 0.002 & 0.91 \\
Temperature*picture valence & $3.19,124.34$ & 2.86 & 0.07 & 0.025
\end{tabular}

Effects of independent variables on picture ratings

\begin{tabular}{lcrrr}
\hline & $\mathbf{d f}$ & $\mathbf{F}$ & \multicolumn{1}{c}{$\mathbf{\eta}^{\mathbf{2}}$} & \multicolumn{1}{c}{$\mathbf{P}$} \\
\hline Temperature & 2,78 & 2.88 & 0.07 & 0.062 \\
Picture valence & $1.35,52.67$ & 213.41 & 0.85 & $<0.001$ \\
Temperature*picture valence & $19.16,558.47$ & 1.34 & 0.03 & 0.264
\end{tabular}

Effects of independent variables on tone ratings

\begin{tabular}{lcccc}
\hline & $\mathbf{d f}$ & $\mathbf{F}$ & $\mathbf{n}^{\mathbf{2}}$ & $\mathbf{P}$ \\
\hline Temperature & 2,78 & 6.05 & 0.13 & 0.004 \\
Picture valence & 2,78 & 7.99 & 0.17 & 0.001 \\
Temperature* picture valence & $2.43,94.78$ & 2.39 & 0.06 & 0.053
\end{tabular}

Effects of independent variables on startle reflex latency

\begin{tabular}{lcccc}
\hline & $\mathbf{d f}$ & $\mathbf{F}$ & $\mathbf{\eta}^{\mathbf{2}}$ & $\mathbf{P}$ \\
\hline Temperature & 2,72 & 0.41 & 0.01 & 0.663 \\
Picture valence & $1.65,59.23$ & 0.87 & 0.02 & 0.406 \\
Temperature*picture valence & $3.12,112.19$ & 1.84 & 0.05 & 0.141
\end{tabular}

Effects of independent variables on startle reflex amplitude

\begin{tabular}{lcccc}
\hline & $\mathbf{d f}$ & $\mathbf{F}$ & $\mathbf{n}^{\mathbf{2}}$ & $\mathbf{P}$ \\
\hline Temperature & 2,72 & 4.19 & 0.10 & 0.019 \\
Picture valence & $1.62,58.46$ & 7.22 & 0.17 & 0.003 \\
Temperature* picture valence & $1.91,68.68$ & 6.50 & 0.15 & 0.003 \\
\hline
\end{tabular}

Significance set at $P<0.05$

Adjusting degrees of freedom with Greenhouse-Geisser correction was necessary when sphericity could not be observed. In case of significant results, post hoc tests (paired-samples $t$ tests) were computed. For $F$ tests, partial eta squared $\left(\eta^{2}\right)$ is reported as an estimate of effect size. In the case of $t$ tests, Cohen's d is reported. SPSS version 14.0 (IBM Corporation, USA) was used for all calculations; significant effects were assumed at $\alpha=0.05$.

\section{EXPERIMENT 2: RESULTS}

Subjective unpleasantness ratings

Temperature ratings: The ANOVA yielded a highly significant main effect of 'temperature condition' (Table 3). As in experiment 1, subjects rated the painful stimulation as quite unpleasant (mean \pm SD $5.76 \pm 2.59)$, followed by 'heat' $(3.88 \pm 2.13)$ and 'warmth' $(2.94 \pm 2.16)$. The 'pain' condition was rated significantly more unpleasant than the 'heat' $(t[39]=8.02, \mathrm{P}<0.001, \mathrm{~d}=1.16)$ and 'warmth' $(t[39]=9.73$, $\mathrm{P}<0.001, \mathrm{~d}=1.66)$ conditions; similarly, the 'heat' condition was rated as more unpleasant than the 'warmth' condition $(t[39]=6.66, \mathrm{P}<0.001$, $\mathrm{d}=0.68)$.

There was no significant main effect for 'picture valence' on the temperature ratings, but there was a significant interaction between 'temperature condition' and 'picture valence' (Table 3). For the 'warmth'

TABLE 4

Descriptive statistics of startle reflex latency and amplitude for each temperature and picture valence condition in experiment 2

\begin{tabular}{|c|c|c|c|c|c|c|c|c|c|c|c|c|c|}
\hline \multirow{2}{*}{$\begin{array}{l}\text { Temperature } \\
\text { Picture }\end{array}$} & & \multicolumn{4}{|c|}{ Warmth } & \multicolumn{4}{|c|}{ Heat } & \multicolumn{4}{|c|}{ Pain } \\
\hline & & Negative & Positive & Neutral & Overall & Negative & Positive & Neutral & Overall & Negative & Positive & Neutral & Overall \\
\hline \multirow[t]{2}{*}{ Latency, ms } & Mean & 65.93 & 60.97 & 61.92 & 62.94 & 62.81 & 63.55 & 61.86 & 62.74 & 61.07 & 63.08 & 62.18 & 62.11 \\
\hline & $\mathrm{SD}$ & 10.31 & 9.92 & 10.84 & 10.36 & 11.09 & 11.38 & 9.24 & 10.57 & 10.17 & 13.92 & 10.51 & 11.53 \\
\hline \multirow[t]{2}{*}{ Amplitude, $\mu \mathrm{V}$} & Mean & 7.14 & 5.96 & 8.20 & 7.10 & 6.96 & 9.23 & 7.79 & 7.99 & 6.56 & 8.62 & 6.62 & 7.27 \\
\hline & $\mathrm{SD}$ & 7.36 & 5.89 & 9.05 & 7.43 & 7.71 & 9.58 & 8.19 & 8.49 & 6.82 & 9.66 & 7.02 & 7.83 \\
\hline
\end{tabular}

condition, temperature was rated as more unpleasant while viewing negative pictures than while viewing positive $(t[39]=2.43, \mathrm{P}=0.020$, $\mathrm{d}=0.39)$ and neutral $(t[39]=2.05, \mathrm{P}=0.047, \mathrm{~d}=0.36)$ pictures; in contrast, picture valence did not influence temperature ratings for the conditions of 'pain' and 'heat' (all $\mathrm{P}>0.05$ ).

Picture unpleasantness ratings: For the picture ratings, the ANOVA yielded a highly significant main effect for 'picture valence' (Table 4). As intended, negative pictures $(6.15 \pm 2.43)$ were rated as significantly more unpleasant than neutral $(1.67 \pm 1.93)$ and positive $(1.39 \pm 1.87)$ pictures (negative - neutral: $t[39]=14.74, \mathrm{P}<0.001, \mathrm{~d}=2.82$; negative positive: $t[39]=16.08, P<0.001, d=3.29$ ). Positive and neutral pictures did not differ significantly in their unpleasantness ratings $(t[39]=1.98$, $\mathrm{P}=0.055, \mathrm{~d}=0.22$ ).

However, these ratings were not affected by the different temperatures, because neither a significant main effect nor a significant interaction was found between temperatures and picture valence on picture ratings (all $\mathrm{P}>0.05$ ).

Tone unpleasantness ratings: For the tone unpleasantness ratings, the ANOVA yielded significant main effects of 'temperature' and 'picture valence' (Table 3). Thus, the subjective evaluation of startle tone unpleasantness was modulated by affective picture content and temperature intensity. Startle tones were rated as more unpleasant while viewing negative pictures and under painful heat, respectively. However, interactive effects of 'temperature condition' and 'picture valence' were not detected on tone ratings.

Summary: Overall, the results obtained from the subjective unpleasantness ratings proved that painful heat stimulation as well as negative pictures elicited moderate to high unpleasantness ratings. Furthermore, both experimental influences were able to modulate the unpleasantness experience for a third variable, namely, the unpleasantness of loud tones.

Startle reflex

Startle reflex latency: With regard to the latency of startle reflexes, the ANOVA yielded no significant effects (all $\mathrm{P}>0.05$; Table 3 ). Descriptive statistics of startle reflex latency are displayed in Table 4. Startle reflex amplitude: Considering the amplitude of startle reflexes as a dependent variable, significant main effects for 'temperature' and 'picture valence' as well as a significant interaction between these two factors were found. To enhance the readability of the findings, these effects are described separately and in detail below.

Main effect 'temperature': Temperature had a significant main effect on the amplitude of startle reflex (Table 3). As can be seen in Table 4, startle reflex amplitude was highest under the condition of 'heat', followed by 'pain' and 'warmth'. Post hoc comparisons using paired samples $t$ tests showed that amplitude was significantly higher for 'heat' than for 'pain' $(t[39]=2.06, P=0.046, d=0.08)$ and significantly higher for 'heat' than for 'warmth' $(t[39]=2.89, \mathrm{P}=0.006, \mathrm{~d}=0.11)$. The comparison between 'pain' and 'warmth' did not reach significance.

Main effect 'picture valence': 'Picture valence' had a significant main effect on the amplitude of startle reflex (Table 3). As can be seen in Figure 4A, this significant effect was due to startle reflex amplitudes being significantly higher for positive compared with negative pictures $(t[39]=2.39 ; \mathrm{P}=0.022 ; \mathrm{d}=0.11)$; all other post hoc $t$ tests failed to reach significance).

Interaction effects: Significant interaction effects between 'temperature' and 'picture valence' were found on the amplitude of the startle 
reflex (Table 3 and Figure 4B). For clarity, these interaction effects (post hoc tests) are described once (a) by focussing on how the effect of 'temperature' on the amplitude of the startle reflex is changed depending on the 'picture valence'; and once (b) by focussing on how the effect of 'picture valence' on the amplitude of the startle reflex is changed depending on 'temperature'.

(a) During the presentation of neutral pictures, startle reflex amplitude was significantly higher for 'warmth' than for 'pain' $(t[39]=3.193$; $\mathrm{P}=0.003, \mathrm{~d}=0.19$ ). During the presentation of positive pictures, amplitude was higher for 'heat' than for 'warmth' $(t[38]=4.423$; $\mathrm{P}<0.0001 ; \mathrm{d}=0.42$ ) and higher for 'pain' than for 'warmth' $(t[37]=2.708 ; \mathrm{P}=0.010 ; \mathrm{d}=0.33)$. There were no significant differences between thermal conditions during the presentation of negative pictures (all $\mathrm{P}>0.05$ ).

(b) Startle reflex amplitude proved to be significantly higher for positive compared with neutral and negative pictures under the conditions of 'pain' (positive - negative: $t[38]=2.45, \mathrm{P}=0.019$, $\mathrm{d}=0.23$; positive - neutral: $t[38]=2.82, \mathrm{P}=0.008, \mathrm{~d}=0.23$ ) and 'heat' (positive - negative: $t[38]=3.76, \mathrm{P}=0.001, \mathrm{~d}=0.24$; positive neutral: $t[38]=2.89, \mathrm{P}=0.006, \mathrm{~d}=0.17$ ). However, this effect was contrary under the condition of 'warmth': Here, reflex amplitude was significantly higher for neutral compared to negative $(t[39)=3.19 ; \quad \mathrm{P}=0.003 ; \mathrm{d}=0.12)$ as well as positive pictures $(t[38]=2.866 ; \mathrm{P}=0.007 ; \mathrm{d}=0.30)$; additionally, it was higher for negative compared to positive pictures $(t[38]=2.720 ; \mathrm{P}=0.010$; $\mathrm{d}=0.20$ ).

Three findings warrant special emphasis.

1. As in experiment 1 , the startle reflex amplitude appeared to be highest under the condition 'heat' and not under the condition 'pain'.

2. In contrast, the ratings suggested the reverse order; in other words, more unpleasantness associated with painful stimulation.

3. Under the condition 'warmth', which likely had the lowest impact on the valence effects of the pictures, startle reflex amplitude was modulated as previously seen by negative and positive pictures, whereas the neutral pictures produced an unusual amplitude enhancement.

\section{DISCUSSION}

We investigated startle reflex modulation by thermal stimulation, which was applied alone (experiment 1) to explore the pure effect of temperature, and then applied concurrently with affective picture presentation (experiment 2) to detect potential interactive effects of these two modalities.

Neither study showed a potentiating effect of tonic heat pain on the startle reflex, although the noxious stimulation was rated as quite unpleasant by the participants. Because startle modulation can be regarded as an objective measure of affective responding (19-21), our results suggest that it is in fact possible to develop a 'safe' noxious stimulation, which is rated as clearly unpleasant - if such ratings from the subjects are required - but lacks physiological indication of negative affect.

Previous findings suggest that the degree of affective pain processing evoked by experimental pain stimuli is highly dependent on situational characteristics such as the perceived threat value associated with pain. A high degree of affective pain processing can be elicited by manipulations relating to anxiety, such as applying stimuli that are not predictable to the subjects $(12-14)$ or by providing threatening instructions $(15,16)$. Accordingly, affective pain responses decrease when the painful experience gets more predictable, possibly mediated by decreased anxiety compared with the levels elicited by unpredictable painful stimuli (34). Considering this evidence, we hypothesized that in a 'safe' (predictable and controllable) experimental situation, the affective component of pain may be reduced to a degree to which it is no longer detectable. To investigate this assumption, we created a 'safe' pain stimulation paradigm by applying tonic heat stimulation of known intensity and course with easy access to control, and measured the startle reflex during this thermal stimulation. The startle reflex was selected as an indicator of affective processing for two reasons: first, emotional startle modulation (ie, potentiation of the startle amplitude by negative affective content) is a very robust finding obtained in many laboratories (35), and second, subjective ratings of pain unpleasantness are known to be prone to response bias $(17,18)$ and are therefore not suitable for investigating the presence or absence of affective processing.

In fact, we did not obtain any startle potentiation during painful versus nonpainful stimulation in either experiment, whereas subjects rated the painful stimulation as rather high in unpleasantness and clearly more unpleasant than nonpainful stimulation. The divergence between startle modulation (as an objective measure of affective responding) and subjective ratings is probably due to the fact that simply by instructing subjects to rate their subjective unpleasantness, they feel inclined to provide higher ratings for the pain condition, thus confusing pain intensity with pain unpleasantness, which has been shown to occur in previous studies $(17,18)$.

Our finding of no startle potentiation during painful thermal stimulation is in conflict with the results obtained by Crombez et al (21), who succeeded in detecting startle potentiation during high intensity $\left(47^{\circ} \mathrm{C}, 49^{\circ} \mathrm{C}\right)$ compared with low intensity $\left(43^{\circ} \mathrm{C}, 45^{\circ} \mathrm{C}\right)$ radiant heat pulses. However, in contrast to our studies, the duration of stimuli applied by these authors was very short $(5 \mathrm{~s})$; in addition, stimuli of different intensities were presented in random order, which prevented the predictability of painfulness of the impending sensations. Taken together, these stimulus characteristics probably rendered the stimulation paradigm less 'safe' than our tonic heat stimulation, which was quite predictable with respect to course and intensity. Taken together, these results suggest that the startle reflex is potentiated by noxious stimulation only if applying painful stimuli in a rather unpredictable manner, but not if applying tonic stimulation of predictable intensity with easy access to control, thus corroborating our assumption that pain can be made 'unemotional' by implementing safety.

However, our findings do not conclusively prove that our painful stimulation was indeed 'unemotional', ie, lacking an affective component. An alternative explanation for the lack of startle potentiation by painful heat may be that noxious stimulation evoked negative affect, but also led to the activation of counter-regulatory processes. It is well-established that tonic pain is able to trigger inhibitory processes that lead to a suppression of concurrently applied phasic pain stimuli ('pain inhibits pain'; 36). This effect is known under the term of conditioned pain modulation (CPM; 37), formerly labelled as descending noxious inhibitory controls. Because CPM was reliably elicited in our laboratory using the same paradigm, namely, tonic contact heat stimulation (38-40), it is very likely that inhibitory processes were also activated in the present study. If so, a pain-induced inhibitory process may have counteracted the potentiation of the startle reflex triggered by the negative emotional valence of pain. A necessary premise of this assumption would be that CPM can not only inhibit pain, but also the unpleasantness of loud tones, which has not yet been investigated. However, there is evidence that CPM also exerts inhibitory effects on subjectively nonpainful heat stimuli (39), indicating that this effect is not necessarily limited to pain. The involvement of both excitatory and inhibitory processes may also explain our surprising finding that 'heat' led to a small but significant startle potentiation in comparison to 'warmth' and 'pain'; at a nonpainful level, heat stimulation may not be sufficiently intense to trigger already inhibitory processes, which may lead to a dominance of excitatory processes and thus to startle potentiation, while at a painful level, inhibitory processes even out the effect of excitatory processes, so that no startle potentiation can be observed.

However, this account is not without alternatives for two reasons. First, subjective ratings indicated that the perception of loud tones was not attenuated by painful stimulation on a subjective level; in 
contrast, tone unpleasantness ratings were highest in the pain condition, indicating that the tonic pain even amplified the perceived unpleasantness of startle tones.

Second, CPM is believed to be controlled by a specific neural circuit, which is far from being identical to that mainly involved in startle reflex modulation. CPM probably exerts inhibitory effects on convergent neurones in the dorsal horn via a spino-bulbo-spinal loop; considerable evidence indicates that the subnucleus reticularis dorsalis in the brainstem is of critical importance for this process (41). In contrast, the startle reflex is regulated by the nucleus reticularis pontis caudalis, which receives input from cochlear root neurons and projects to motoneurons in the facial motor nucleus, which in turn elicit the motor response (eg, blinking). Affective states modulate the startle reflex via projections from the amygdala and the bed nucleus of the stria terminalis on the nucleus reticularis pontis caudalis $(25,42)$. From this physiological point of view, it appears rather unlikely that the startle reflex was altered by CPM.

We conducted experiment 2 because we were interested in the interaction between the affective component of pain and the positive and negative emotions induced by picture viewing in startle reflex modulation. For this purpose, we used the concurrent presentation of affective pictures and thermal stimulation to explore whether we would detect independent or interactive effects of these two stimulus modalities on the startle reflex (see "Experiment 2: Introduction" above, and Figure 3). As expected, we found unique effects (as in experiment 1 , startle reflex amplitude was the highest under the 'heat' condition [main effect temperature] and overall positive pictures elicited highest amplitude values [main effect picture]) as well as interactive effects (indicated by a significant interaction) of affective pictures and thermal stimulation on the startle reflex amplitude. Given that the interaction effects were of most interest, these will be discussed in more detail below.

The interaction between affective pictures and thermal stimulation displayed a rather complex interplay between these two modalities. Affective pictures exerted different effects on the startle reflex depending on 'temperature condition'. During the condition of 'warmth', which served as a neutral control condition for selectively assessing the impact of affective pictures, our findings are mostly in agreement with previous studies (22-25), namely, that startle amplitude is higher for negative compared with positive pictures (the only unusual result was an amplitude enhancement during neutral in comparison with negative pictures). Interestingly, this pattern changed during 'pain' and 'heat' conditions. Here, startle amplitude was highest for positive pictures. These results indicate that intense tonic heat stimulation may even change the emotional valence of concurrently presented pictures, shifting positive valence to the negative pole. Godinho et al (31) already observed that painful electrical stimuli led to changes in brain activation in response to positive pictures, by rendering them less pleasant. This is particularly interesting because we also mainly detected effects for positive pictures, while the startle amplitude obtained during negative pictures remained unchanged by temperature conditions. An alternative account might be provided by theories of attentional interference. It is known that individuals show a slowing of reaction time in response to a target stimulus if they were previously primed with a stimulus that is affectively incongruent to the target; this is probably due to more attentional interference caused by an incongruent prime (43). Maybe pain - which is a potent distractor in itself (44) - led to more attentional interference when priming a positive (and thus incongruent) stimulus, thus disengaging the attentional focus from the affective pictures. The dampening of attention for the positive pictures or even the incongruence itself may have led to the failure of finding the usual reduction of startle amplitude. However, both of these explanations are mere speculation and further clarification is required in future research.

As for subjective ratings of the different temperatures, we found a significant interaction that partly showed a similar interactive pattern. Mirroring the findings for the reflex amplitude, subjective temperature ratings of the 'warmth' intensity also changed depending on the picture valence, with highest ratings during negative pictures compared with viewing positive or neutral pictures. During 'heat' and 'pain' conditions, temperature ratings remained unaffected by the type of pictures presented.

In contrast, thermal stimulation exerted different effects on the startle reflex depending on 'picture valence'. Interestingly, startle amplitude was higher during 'pain' compared with the 'warmth' condition only when viewing positive pictures, whereas opposite effects were found while viewing neutral pictures (see "Startle reflex amplitude" above.). Even more surprisingly, however, was that the different intensities of the thermal stimulation did not change startle amplitude while viewing negative pictures. It is possible that the negative pictures were so negatively arousing that attention shifted away from the thermal stimulation (thus rendering temperature to be irrelevant). Similar effects have already been observed for highly arousing positive pictures, namely erotic pictures (45). As for subjective ratings of the pictures, these were not affected by the different temperatures intensities.

Taken together, our results suggest a complex two-way interaction of thermal stimulation and affective pictures on the startle reflex. Therefore, temperature and picture effects are not independent, which also means that thermal stimulation - even if unemotional in itself exerts effects on emotional processing. This may be due to direct effects of emotional blending or to distraction or to other unknown factors.

\section{LIMITATIONS AND FUTURE DIRECTIONS}

Although we were able to show high reliability of our findings by replicating the results of experiment 1 in experiment 2, there are some methodological issues that are worth addressing.

First, because our aim was to develop a 'safe' pain condition of high intensity (to ensure that a lack of emotional responding would not have been trivial), we did not vary the degree of threat associated with experimental pain at this stage of our research. As differences in 'threatfulness' rather than in painfulness might explain the differences in results between our study and the study of Crombez et al (21), these two factors should be manipulated independently from each other in the future.

Second, our paradigm using the presentation of affective pictures in experiment 2 was unusual in comparison to other startle reflex studies. Most researchers investigating affective startle modulation use presentation times of $6 \mathrm{~s}$ per picture and present the pictures randomized across valence categories. In contrast, we presented each picture for nearly $60 \mathrm{~s}$ to match the tonic nature of thermal stimulation and pictures of the same valence category were clustered in blocks of six. Accordingly, the level of novelty of affective stimulation was lower and, thus, presumably the level of arousal, which might have attenuated the modulating effect of affective pictures on startle.

Third, we selected affective pictures that did not score very high in valence and arousal ratings, to match the presumed affective impact of our thermal stimulation. However, several authors found that modulating effects on startle reflex are strongest when presenting high arousing pictures (ranging around 7.0 compared with 5.0 in our study) and sometimes even failed to occur when presenting pictures that are not as arousing (46-48).

Fourth, we did not assess individual differences in trait anxiety, which might be relevant for explaining some variability in startle responses; we plan to include such anxiety measures in our future research.

\section{CONCLUSIONS}

Our two experiments showed no potentiation of the startle reflex by tonic heat pain stimulation. Therefore, our results indicate that it is possible to develop a 'safe' noxious stimulation (of known intensity and course with easy access to control), which is rated as clearly unpleasant, but lacks physiological indication of negative affect. In other words, pain is not necessarily associated with an unpleasant 
component, although the pain definition by the International Association for the Study of Pain suggests a different story (49). In line with preliminary research, we propose that situational demand characteristics affecting the perception of threat, which can be independent from the intensity of nociceptive stimulation, play a major role in the activation of affective pain processing.

APPENDIX 1: The IAPS identification numbers were as follows: Positive pictures: 1640, 1720, 4180, 4255, 4533, 4601, 4609, 4617, 4645,

\section{REFERENCES}

1. Price DD, Harkins SW. The affective-motivational dimension of pain. A two-stage model. APS J 1992;1:229-39.

2. Price DD, McGrath PA, Rafii A, Buckingham B. The validation of visual analogue scales as ratio scale measures for chronic and experimental pain. Pain 1983;17:45-56.

3. Price DD, Harkins SW. The combined use of visual analogue scales and experimental pain in providing standardized assessment of clinical pain. Clin J Pain 1987;3:3-11.

4. Price DD. Neural and psychological mechanisms of the affective dimension of pain. Science 2000;9:1769-72.

5. Strigo IA, Bushnell MC, Boivin M, Duncan GH. Psychophysical analysis of visceral and cutaneous pain in human subjects. Pain 2002;97:235-46.

6. Dunckley P, Wise RG, Aziz Q, Painter D, Brooks J, Tracey I, Chang L. Cortical processing of visceral and somatic stimulation: Differentiating pain intensity from unpleasantness. Neuroscience 2005; 133:533-42.

7. Chen AC, Treede RD, Bromm B. Tonic pain inhibits phasic pain: Evoked cerebral potential correlates in man. Psychiat Res 1985;14:343-51.

8. Rainville P, Feine JS, Bushnell MC, Duncan GH. A psychophysical comparison of sensory and affective responses to four modalities of experimental pain. Somatosens Mot Res 1992;9:265-77.

9. Lautenbacher S, Roscher S, Strian F. Tonic pain evoked by pulsating heat: Temporal summation mechanisms and perceptual qualities. Somatosens Mot Res 1995;12:59-70.

10. Villemure C, Slotnick BM, Bushnell MC. Effects of odors on pain perception: Deciphering the roles of emotion and attention. Pain 2003;106:101-8.

11. Loggia ML, Mogil JS, Bushnell MC. Experimentally induced mood changes preferentially affect pain unpleasantness. Pain 2008;9:784-91.

12. Johnson JE. Effects of accurate expectations about sensations on the sensory and distress components of pain. J Pers Soc Psychol 1973;27:261-75.

13. Price DD, Barrell JJ, Gracely RH. A psychophysical analysis of experiential factors that selectively influence the affective dimension of pain. Pain 1980;8:137-49.

14. Carlsson K, Andersson J, Petrovic P, Petersson KM, Ohman A, Ingvar M. Predictability modulates the affective and sensorydiscriminative neural processing of pain. Neuroimage 2006;32:1804-14.

15. Boston A, Sharpe L. The role of threat-expectancy in acute pain: Effects on attentional bias, coping strategy effectiveness and response to pain. Pain 2005;119:168-75.

16. Jackson T, Pope L, Nagasaka T, Fritch A, Iezzi T, Chen H. The impact of threatening information about pain on coping and pain tolerance. Brit J Health Psych 2005;10:441-51.

17. Fernandez E, Turk DC. Demand characteristics underlying differential ratings of sensory versus affective components of pain. J Behav Med 1994;17:375-90.

18. Chapman CH, Nakamura Y, Donaldson GW, et al. Sensory and affective dimensions of pain are indistinguishable in the self-report and psychophysiology of normal subjects. Pain 2001;2:279-94.

19. Grillon C, Ameli R, Woods SW, Merikangas K, Davis M. Fear-potentiated startle in humans: Effects of anticipatory anxiety on the acoustic blink reflex. Psychophysiology 1991;28:588-95.

20. Yartz AR, Hawk LW. Addressing the specificity of affective startle modulation: Fear versus disgust. Biol Psychol 2002;59:55-68.

21. Crombez G, Baeyens F, Vansteeenwegen D, Eelen P. Startle intensification during painful heat. Eur J Pain 1997;1:87-94.

22. Lang PJ, Bradley MM, Cuthbert BN. Emotion, attention, and the startle reflex. Psychological Rev 1990;97:377-95.
4653, 7220, 7289, 7400, 7481, 8021, 8041, 8220, 8371; Negative pictures: $1274,2710,3017,3160,3181,3220,6200,6244,6571,7359,8230,9426$, 9429, 9520, 9530, 9621, 9911, 9925; Neutral pictures: 2104, 2440, 7000, 7002, 7006, 7010, 7020, 7025, 7031, 7036, 7050, 7055, 7059, 7150, 7224, $7590,7595,7705$.

DISCLOSURE: The authors have no finacial disclosures or conflicts of interest to declare.

23. Bradley MM, Vrana SR. The startle probe in the study of emotion and emotional disorders. In: Birbaumer N, Öhman A, eds. The Structure of Emotion. Seattle: Hogrefe and Huber, 1993:270-87.

24. Lang PJ. The emotion probe: Studies of motivation and attention. Am Psychol 1995;50:372-85.

25. Grillon C, Baas J. A review of the modulation of the startle reflex by affective states and its application in psychiatry. Clin Neurophysiol 2003;114:1557-79.

26. Meagher MW, Arnau RC, Rhudy JL. Pain and emotion: Effects of affective picture modulation. Pschosom Med 2001;63:79-90.

27. Kenntner-Mabiala R, Pauli P. Affective modulation of brain potentials to painful and nonpainful stimuli. Psychophysiology 2005;42:559-67.

28. Rhudy JL, Williams AE, McCabe KM, Nguyen MA, Rambo PL. Affective modulation of nociception at spinal and supraspinal levels. Psychophysiology 2005;42:579-87.

29. Kenntner-Mabiala R, Weyers P, Pauli P. Independent effects of emotion and attention on sensory and affective pain perception. Cognition Emotion 2007;21:1615-29.

30. Roy M, Piché M, Chen JI, Peretz I, Rainville P. Cerebral and spinal modulation of pain by emotions. PNAS 2009;106:20900-5.

31. Godinho F, Frot M, Perchet C, Magnin M, Garcia-Larrea L. Pain influences hedonic assessment of visual inputs. Eur J Neurosci 2008;27:2219-28.

32. Lang PJ, Bradley MM, Cuthbert BN. International affective picture system (IAPS): Digitized photographs, instruction manual and affective ratings. Technical Report A-6. Gainesville: University of Florida, 2005.

33. Lang PJ. Self-assessment manikin. Gainesville, FL: The Center for Resarch in Psychophysiology, University of Florida, 1980.

34. Rhudy JL, Meagher MW. Fear and anxiety: Divergent effects on human pain thresholds. Pain 2000;84:65-75.

35. Bradley MM, Cuthbert BN, Lang PJ. Affect and the startle reflex. In: Dawson ME, Schell A, Boehmelt A, eds. Startle modification: Implications for neuroscience, cognitive science and clinical science. New York: Cambridge University Press, 1999:157-83.

36. Moont R, Pud D, Sprecher E, Sharvit G, Yarnitsky D. 'Pain inhibits pain' mechanisms: Is pain modulation simply due to distraction? Pain 2010;150:113-20.

37. Yarnitsky D, Arendt-Nielsen L, Bouhassira D, et al. Recommendations on terminology and practice of psychophysical DNIC testing. Eur J Pain 2010;14:339.

38. Lautenbacher S, Rollman GB. Possible deficiencies of pain modulation in fibromyalgia. Clin J Pain 1997;13:189-96.

39. Lautenbacher S, Roscher S, Strian F. Inhibitory effects do not depend on the subjective experience of pain during heterotopic noxious conditioning stimulation (HNCS): A contribution to the psychophysics of pain inhibition. Eur J Pain 2002;6:365-74.

40. Lautenbacher S, Prager M, Rollman GB. Pain additivity, diffuse noxious inhibitory controls, and attention: A functional measurement analysis. Somatosens Mot Res 2007;24:189-201.

41. Villanueva L, Le Bars D. The activation of bulbo-spinal controls by peripheral nociceptive inputs: Diffuse noxious inhibitory controls. Biol Res 1995;28:113-25.

42. Davis M, Walker DL, Lee Y. Neurophysiology and neuropharmacology of startle and its affective modulation. In: Dawson ME, Schell AM, Bömehlt AH, eds. Startle Modification. Implications for Neuroscience, Cognitive Science and Clinical Science. New York: Cambridge University Press, 1999:95-113.

43. Wentura D. Activation and inhibition of affective information: Evidence for negative priming in the evaluation task. Cognition Emotion 1999;13:65-91. 
44. Crombez G, Eccleston C, Baeyens F, Eeelen P. The disruptive nature of pain: An experimental investigation. Behav Res Ther 1996;34:911-18.

45. Schimmack U. Attentional interference effects of emotional pictures: Threat, negativity, or arousal? Emotion 2005;5:55-66.

46. Cuthbert BN, Bradley MM, Lang PJ. Probing picture perception: Activation and emotion. Psychophysiology 1996;33:103-11.

47. Bradley MM, Cuthbert BN, Lang PJ. Affect and the startle reflex. In: Dawson ME, Schell A, Boehmelt A, eds. Startle Modification.
Implications for Neuroscience, Cognitive Science and Clinical Science. New York: Cambridge University Press, 1999:157-83.

48. Bernat E, Patrick CJ, Benning SD, Tellegen E. Effects of picture content and intensity on affective physiological response. Psychophysiology 2006;43:93-103.

49. International Association for the Study of Pain (IASP). Pain terms: A list with definitions and notes on usage. Pain 1979;6:249-52. 


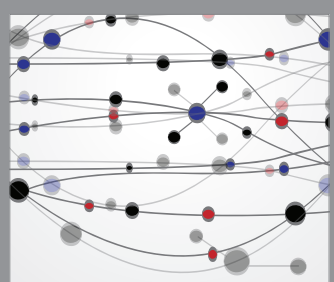

The Scientific World Journal
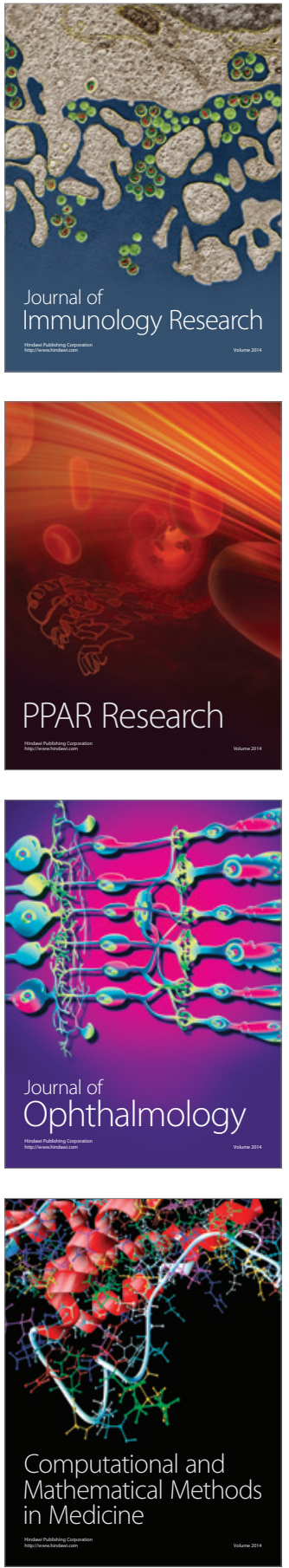

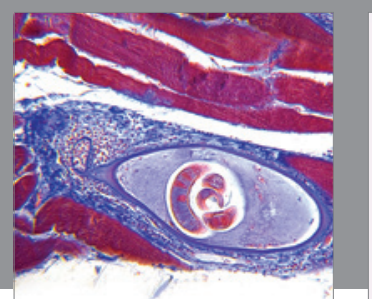

Gastroenterology Research and Practice

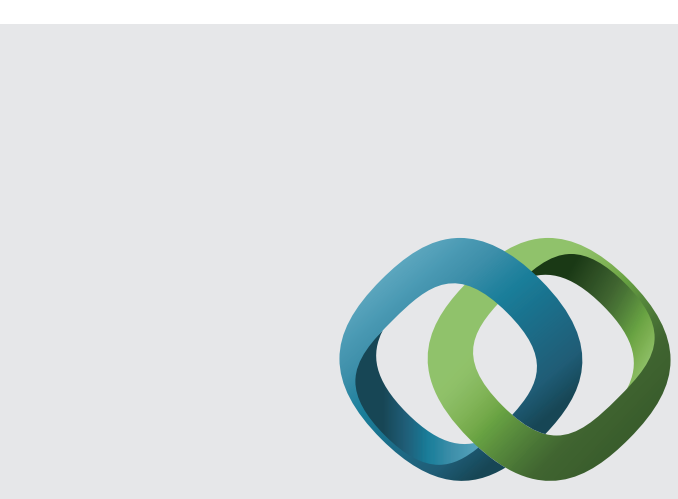

\section{Hindawi}

Submit your manuscripts at

http://www.hindawi.com
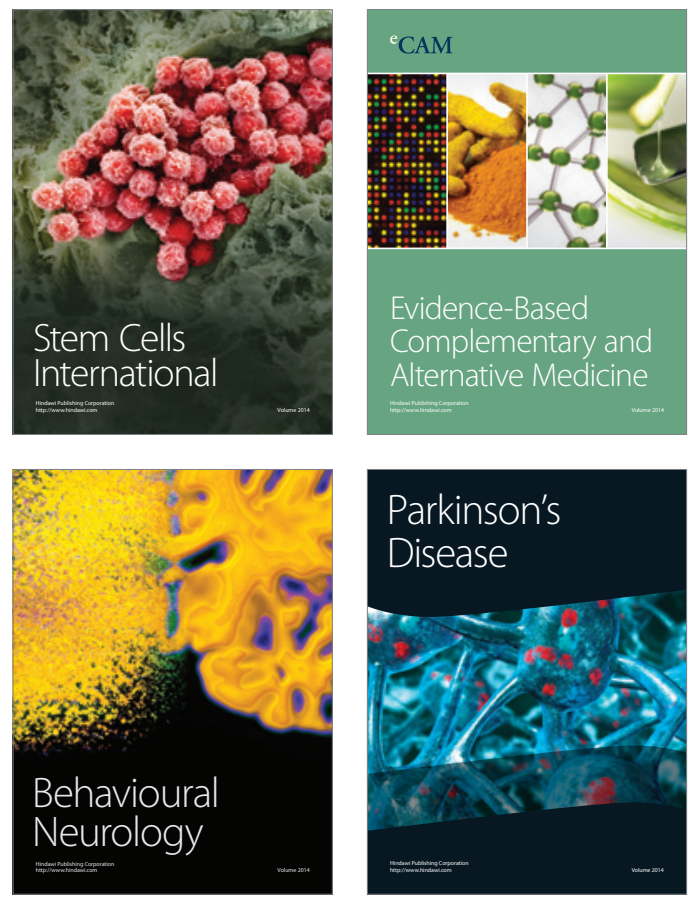
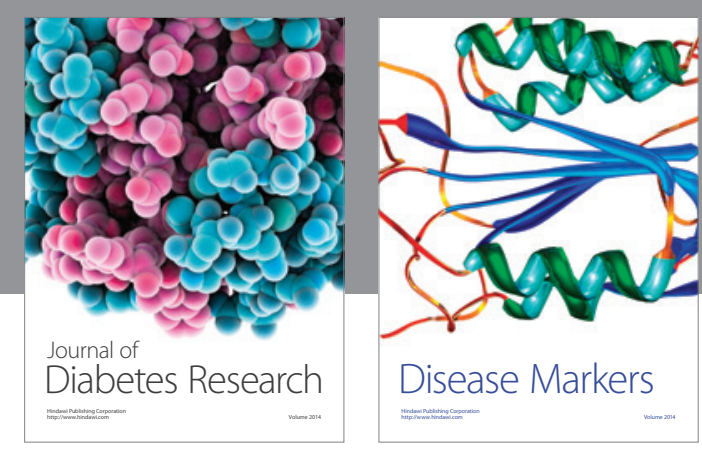

Disease Markers
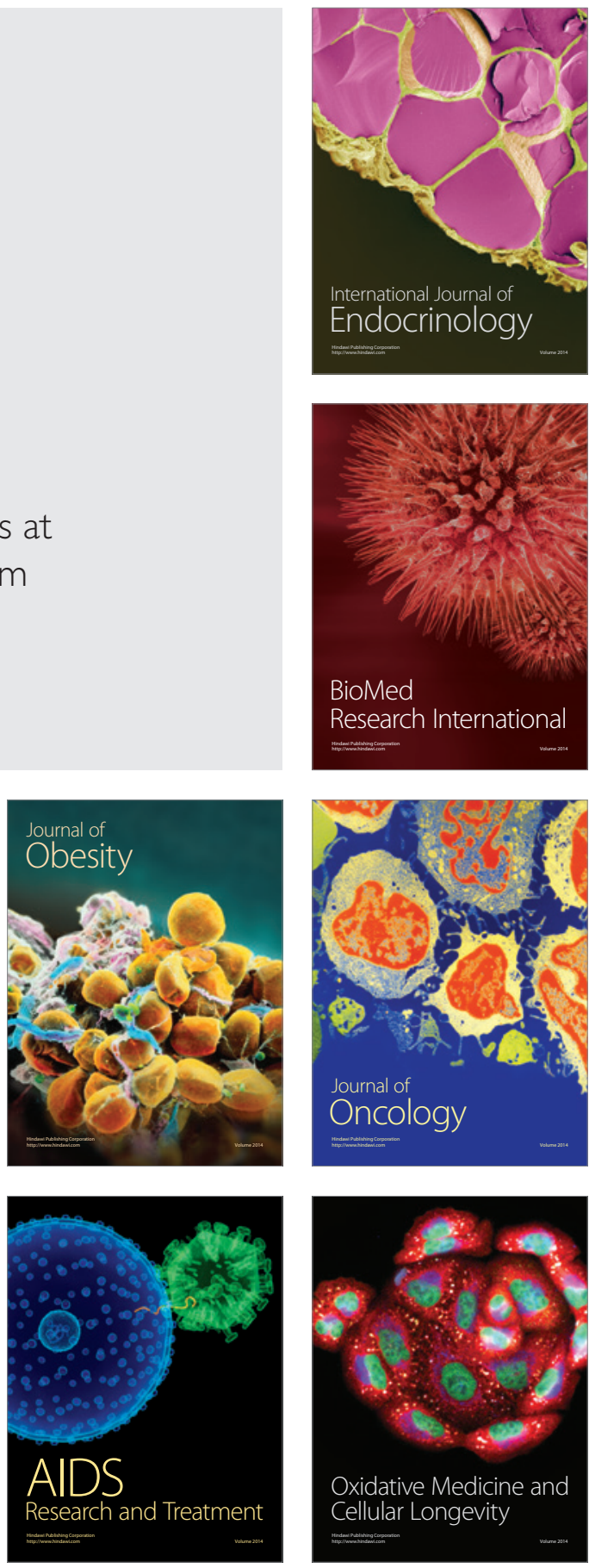